USBAD Uluslararası Sosyal Bilimler Akademi Dergisi -

International Journal of Social Sciences Academy, YIl 2, Year

2, Sayı 4, Issue 4, Aralık 2020, December 2020.

e Issn: 2687-2641

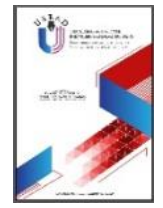

\title{
KÜRESELLEŞMENİN POST'LARI: POST-MODERNİZM, POST-TRUTH VE POST-COVID
}

"POST"S OF GLOBALIZATION: POST-MODERNISM, POST-TRUTH AND POST-COVID

\section{Samet ZENGİNOĞLU}

Dr. Öğr. Üyesi, Dış Ticaret Bölümü, Sosyal Bilimler Meslek Yüksekokulu, Adıyaman Üniversitesi,

Adıyaman/Türkiye.

Asst. Prof. Dr., Department of Foreign Trade, Vocational School of Social Sciences, Adıyaman University,

Adıyaman/Turkey.

sametzenginoglu@gmail.com

ORCID ID: 0000-0001-6061-8388

\section{Makale bilgisi | Article Information} Doİ: 10.47994/usbad.794635

Makale Türü / Article Type: Araştırma Makalesi / Research Article

Geliş Tarihi / Date Received: 14.09.2020

Kabul Tarihi / Date Accepted: 22.11.2020

Yayın Tarihi / Date Published: 20.12.2020 Yayın Sezonu / Pub Date Season: Aralık / December

Bu Makaleye Atıf İçin / To Cite This Article: Zenginoğlu, S. (2020). Küreselleşmenin Post'ları: Post-Modernizm, Post-Truth ve Post-Covid. USBAD Uluslararası Sosyal Bilimler Akademi Dergisi 2(4), 805-817.

İntihal: Bu makale intihal.net yazılımınca taranmıştır. İntihal tespit edilmemiştir. Plagiarism: This article has been scanned by intihal.net. No plagiarism detected.

\section{intihal.net}

İletişim: Web: https://dergipark.org.tr/tr/pub/usbad mail: usbaddergi@gmail.com 
Öz: İnsanlık, tarih boyunca dünyanın farklı bölgelerinde çeşitli salgınlarla yüzleşmiştir. Bu salgınlar gerek süreçleri gerekse de sonuçları itibariyle birçok farklı etkiye sahip olmuşlardır. 21. yüzyılın ilk çeyreğinde Çin'in Wuhan kentinde ortaya çıkan ve sonrasında bütün dünyayı etkisi altına alan Covid19 salgını ile karşılaşılmıştır. Salgın, birçok ülkenin sağlık sisteminde, ekonomik ve politik yapısında küçük, orta ve büyük ölçekli fay hatları oluşturmuş̧tur. Dolayısıyla başta tıp olmak üzere, iktisat, politika, yönetim, siyaset bilimi, uluslararası ilişkiler alanlarında salgının süreç ve sonuçlarına dair görüşler ortaya konmuş ve hızla büyüyen bir literatür ortaya çıkmıştır. Elbette ki sürecin açıklanması adına bu görüşlere ve literatüre intiyaç duyulduğu bir gerçektir. Lakin sosyal bilimler adına bu denli kısa bir zaman dilimi içerisinde salgının sonrasında "post" eksenli analizler özelinde temkinli olunması gerektiği düşünülmektedir. Bu düşünceden hareketle bu çalışma temkinli olmayı göz önünde bulundurarak aslında bu sürecin küreselleşme ve post-modernizm ilişkisi nazarında doğal kabul edilmesi gerektiği savına sahip bulunmaktadır. Özellikle post-truth kavramı ile birlikte post-Covid söyleminin belirsizlik içerisinde daha da belirginleşeceği kanaati söz konusudur.

Anahtar Kelimeler: Küreselleşme, Post-Modernizm, Post-Truth, Post-Covid

Abstract: The humankind has faced various pandemics in different areas of the world throughout history. These pandemics have had numerous different effects in terms of their processes and outcomes. The humankind faced the Covid-19 pandemic which appeared in Wuhan, China in the first quarter of $21^{\text {st }}$ century to affect the whole world afterwards. The pandemic has created small, medium and large-scaled fault lines in the health systems, economic and political structures of several countries. Therefore, opinions have been proposed regarding the process and outcomes of the pandemic particularly in terms of medicine, economics, politics, management, political science and international relations to create an ever-growing literature. These opinions and literature are certainly needed for the explanation of the process. But in terms of social sciences, it is believed that one needs to be cautious regarding the "post"-pandemic analyses in such a short time period. In this respect, the paper claims that this process actually needs to be considered natural in terms of the process' relationship with globalization and post-modernism in line with this cautiousness. There is belief that post-Covid discourse will become more evident in uncertainty particularly with the post-truth concept.

Keywords: Globalization, Post-Modernism, Post-Truth, Post-Covid

\section{GİRIŞ}

21. yüzyıl, kendisinden önceki tarihi dönemlerle kıyaslandığında kuramsal ve pratik alanda çok daha fazla anahtar kelime ile analiz edilebilecek bir düzeye erişmiştir. Bir yandan küreselleşmenin çokboyutlu bağlamı, diğer yandan kuramsal, ekonomi-politik ve sosyo- 
psikolojik alanlarda yaşanan yoğun muhtevaya sahip gelişmeler girift bir tablo ortaya çıkarmıştır. Lakin bu girift tablo küreselleşmenin post'ları (sonra, sonrası, sonraki) itibariyle daimî surette kendisini güncellemiştir. Her ne kadar ifade edilen alanlarda yaşanan krizler bir "son" düşüncesini akla getirse de küreselleşme kendi perspektifi içerisinde bu krizleri yapısına adapte edebilmiştir. Kuram ve söylem ekseninde çalışma, işaret edilen post'ların küreselleşmenin belirsiz güzergahına yön verdiği savına sahiptir. Dolayısıyla adaptasyon ve belirsiz güzergahın tayini, güncellenen belirsizliğe de atıfta bulunmaktadır. Gerçeklik ve hakikat eksenli tartışmalarda postmodernizm ve post-truth küreselleşme adına ideal zemini inşa etmişlerdir/etmektedirler. Bu nedenle bu çalışmada post-Covid söyleminin de benzer bir zemine sahip olduğu düşünülmektedir.

2019 yılının sonlarında Çin'in Wuhan kentinde ortaya çıkan Covid19 (Koronavirüs) ekseninde 11 Mart 2020 tarihinde Dünya Sağlık Örgütü tarafından pandemi ilan edilmiştir ve hem akademinin çeşitli disiplinleri hem muhtelif medya vasıtaları/mensupları süreci irdeleyen çalışmalar ortaya koymuşladır. Ayrıca süreçten ziyade sonraya odaklanan çalışmalar da bu perspektifte dikkat çekmiştir. Elbette ki her salgın farklı yansımalarla yine bir o kadar farklı sonuçları beraberinde getirmiştir. Örneğin Nikiforuk'un ifadesi ile (2013: 269) cüzzam hastaneleri yaratmış, sıtma ırkçıı̆ı teşvik etmiş, veba feodalizmi yenmiş, tüberküloz evlerin tabanlarına mantarlı muşamba döşemiştir. Lakin Covid-19 adına henüz süreç konusunda bile mutabık kalınamadığını söylemek yanlış olmayacaktır. Salgına dair; salgının etkisi üzerindeki "ırk" temelli analizlerden başlanarak aslında bu sorunun bir devletin ya da kişinin "oyunu" olduğuna dair açıklamalara değin birçok örnek vermek olasıdır. Ancak akademik çalışmaların çoğu popülist söylemin "gerçekliğe" üstün gelmesi ve dolayısıyla irrasyonel olanın rasyonel olandan daha fazla taraftar bulmasının olumsuzluğu üzerine olması gerekliğinden hareketle (Güven, 2020: 21) bu çalışma ilgili sav ekseninde üç başlık/bölüm üzerine inşa edilmiştir.

"Küreselleşme ve Post-Modernizm: Güncellenen Belirsizlik" başlığını taşıyan birinci bölümde, küreselleşme olgusuna yönelik yaklaşımlar ele alınmış ve bunu müteakiben post-modernizm ile ilintili bağlam ortaya konulmuştur. Bu bağlamın belirsizlik nazarındaki güncelleme boyutuna vurgu yapılmıştır. Hakikat-sonrası olarak da tanımlanan post-truth kavramına odaklanan "Post-Truth ya da Çağın Hakikati" başlıklı bölümde ise birinci bölümden hareketle hakikate dair 
tartışmaların nasıl çağın hakikati olarak açıklanabileceği analiz edilmiştir. Son olarak üçüncü bölümde "Post-Covid: Bitmeden Başlamak Mümkün mü?" başlıklı soru ile de pandemi sürecine dair "post" tartışmaları ele alınmıştır.

\section{KÜRESELLEŞME VE POST-MODERNİZM: GÜNCELLENEN BELİRSİZLIKK}

Küreselleşme, McLuhan'dan (1964) bu yana kuramsal olarak ve özellikle 1990'lar itibariyle fiilen politik, ekonomik, kültürel ve toplumsal hayatımızı etkileyen bir olgudur. Ticaretin serbestleşme alanları, ekonomik ilişkilerde artan etkileşim düzeyi, terörizmin küresel bir boyuta evrilmesi, göç konusunun ulus-aşırı bir kapsamda değerlendirilmesi, kültürel kapitalizm tartışmaları nazarında tektipleşme sorunsalının gündeme gelmesi gibi faktörler ve gelişmeler dahilinde bu etkilerin yansımalarını görebilmek mümkündür. Bu "çokboyutlu" fenomen (Tomlinson, 2013: 27), kendi bağlamında birtakım ikilemler intiva etmiş ve yine fenomenin anlamlandırılması adına çeşitli yaklaşımlar geliştirilmiştir. Örneğin ikilemler açısından, küreselleşmenin Soğuk Savaş'ın tanımlayıcı perspektifi olan "bölünme"nin aksine "bütünleşme"yi ön plana çıkardığı savına (Friedman, 2010: 31) karşın, esasında bütünleşmenin tek-tipleşmeyi beraberinde getirdiği savı da tartışmalardaki yerini almıştır. Guenon'un (2020: 73) "dünya ne kadar çok tekbiçimleşmişse, kelimenin gerçek anlamıyla, o kadar az birleşmiş durumdadır" görüşünden hareket edildiğinde bir bakıma bütünleşmeye karşın farklılıkların ve farklılaşmanın da ayrı bir bağlamı oluşturduğu gerçeği ile karşılaşılmıştır. Dolayısıyla bu girift tablo, ifade edildiği üzere küreselleşmenin anlamlandırıması amacıyla üç temel yaklaşımı beraberinde getirmiştir.

Küreselleşmeye dair ilgili yaklaşımları, aşırı küreselleşmeciler, şüpheciler/kuşkucular ve dönüşümcüler olmak üzere üç temel başlık altında analiz etmek olanakıdır. Çalışma açısından özellikle dönüşümcülere dair argümanlar önem arz etmektedir. Zira dönüşümcüler, hem aşırı küreselleşmecilerin "ulus devlet" egemenliğinin sonuna gelindiği iddiasına hem de şüphecilerin/kuşkucuların esasında hiçbir şeyin değişmediği iddiasına karşı çıkmakta ve küreselleşmeyi gerek modern toplumları gerek dünya düzenini yeniden şekillendiren politik, ekonomik ve toplumsal değişmelerin arkasındaki temel faktör olarak değerlendirmektedir (Kaya, 2019: 1-13). Bu noktada, modern dönemin mirası ile birlikte ve 
ona karşı müşahede edilen yeniden şekillenme ve ortaya çıkan değişmeler ile küreselleşmeyle dirsek teması halinde bir yön arayışı içerisinde olan post-modernizmin ilgili ve ilişkili olduğu düşünülmektedir. Çünkü dönüşümcülerin, aşırı küreselleşmeciler ya da şüpheciler/kuşkucular kadar net bir yön tayin etmemeleri ve deyim yerindeyse değişimin etkilerini yorumlamaları bir bakıma post-modern söylemin doğal bir tezahürü olarak da addedilebilmektedir.

İfade edilen tezahürü flu bir boyuttan daha belirgin bir boyuta taşıyan anahtar kavramlardan birisinin "müphemlik" olması ise süreci ve içeriği daha da manidar kılmaktadır. Bauman'ın (2014: 104) esasında net bir biçimde üzerinde durduğu bu kavram, içerisinde bulunduğumuz zaman dilimindeki egemen duygunun yeni tip bir belirsizlik duygusu olduğuna işaret etmektedir. Lakin ilginç bulunabilecek ya da doğal kabul edilebilecek husus post-modernliğin belirsizlik yorumunda yeni olan başka bir şeyin de bunun artık belli bir çabayla azaltılabilecek veya tamamen üstesinden gelinebilecek geçici bir dert olarak görülmemesidir. Dolayısıyla post-modern dünya, kendisini, daimî ve azaltılamaz bir belirsizlik koşulu altında bir yaşama hazırlamaktadır (Bauman, 2013: 36). Şeylerin ya da durumların belirsiz olduğu ifade edildiğinde, neler olacağından emin olunmaması durumu kast edilmektedir. Bu durumda insanlar nasıl davranacaklarını ve bu davranışların sonuçlarını kestirememektedirler (Artan Özoran ve Mermer, 2018: 311; Koyuncu, 2019). Kaosun verili olduğu dünyada insanın mutlak bir düzen pratiği kuramaması durumu sebebiyle kaosdüzen ikileminde algılanan dünyadaki "kesinlik arayışının sonuçlanamaması" değerlendirmesi ile karşılaşılmaktadır (Başer, 2011: 1).

Esas itibariyle bu tartışma yeni bir tartışma da değildir. Nitekim Rorty ve Vattimo'nun (2009: 12) "Dinin Geleceği"ni tartıştıkları eserin giriş bölümünde artık ne Aydınlanma öncesi gibi belirgin bir "inanç çağı"ndan ne de Aydınlanma sonrası gibi belirgin bir "akıl çağı"ndan söz edilebileceği ve sonucun bizatihi bir "yorum çağı" olduğu tezi bu noktada akla gelen bir örneği temsil etmektedir. Zira 20. yüzyıldaki insanın payına düşen şey genel bir belirsizlik olmuştur ve insan kesinlikler cennetini yitirmiştir (Russ, 2014: 18-19). Bu nokta, çalışmanın temel savı açısından kilit konumda yer almaktadır. Çünkü post-modernizmin salık verdiği belirsizlik/müphemlik ile ortaya konulan her bir yorum -bu çalışma dahil olmak üzere- küreselleşmenin güncellenmesi adına yeni bir adımı teşkil etmektedir. Üçüncü bölümde 
ifade edileceği üzere, Covid-19'a dair kısa sürede geliştirilen "post" söylemlerinin bu adımlardan birisini oluşturduğu düşünülmektedir. Çünkü mevcudun tanımlanamaması ya da açıklanamaması kuramsal zeminde post-modernizmin küreselleşme ile eş zamanlı sunduğu belirsizliği onaylar/destekler mahiyettedir.

Bu güncelleme bir başka ve benzer eksende post-truth kavramı ile karşılaşılmasını sağlamaktadır. Nitekim post-modernizm ile post-truth arasında güçlü bir bağ(lam) söz konusudur. Şöyle ki, post-modern filozoflar, objektif gerçekliği sorgulayarak hakikat olgusunu da yapı bozumuna uğratmaya çalışmaktadırlar. Dolayısıyla modern dönem mutlak hakikati, değişmezliği, itaati ve nesnelliği desteklerken, postmodern görüşler modernizmin getirdiği mutlak hakikat görüşünü eleştirip yapı bozumuna uğratmaktadırlar (Günenç, 2019: 26). "Postmodern teorisyenlerin hiçbiri, günümüzün betimlemekte oldukları berbat koşullarına yeterli bir politik yanıt formülleştirmemiştir" (Best ve Kellner, 2011: 341). Dolayısıyla post-modernizm, post-truth teriminin tanımlanması ve post-truth hakkında konuşulabilmesi için kullanışlı bir sözlük sağlama noktasında uygun bir zemin oluşturmaktadır (Günenç, 2019: 29). Bu zeminde hakikatin izafiliği vurgulanmaktadır (Güven, 2020: 27-28). Hakikatin farklı görünümleri de bir bakıma belirsiz görünümleri ortaya çıkarmaktadır. Belirsiz görünümlerin, hakikatin izafiliği noktasındaki teşhis ve tespitler yorumları beraberinde getirmektedir. Elbette ki post-modernizm ve post-truth birlikteliğini bu noktada tek başına düşünmemek gerekmektedir. Zira küreselleşmenin neden ya da sonuçlarının da birlikte değerlendirilmesi gerektiği düşünülmektedir. Postmodernizmin getirileri ile bir tür hesaplaşma içine girmiş olan Keyes'in (2019) post-truth'u teknolojinin ilerlemesinden kuvvet alarak yalancılığı besleyen yozlaşmış toplumların yaşadığı çağın adı olarak nitelendirmesi (Akt. Aslan, 2020: 111) zikredilen neden-sonuç perspektifinde önemli görülmektedir.

\section{POST-TRUTH YA DA ÇAĞIN HAKİKATİ}

Aristoteles'in "olan şeye yok ya da olmayan şeye var demek yanlış, olan şeye var ve olmayan şeye yok demek doğrudur" ifadesindeki yüklemlerin yerleri değiştirildiğinde post-truth kavramına atfen çağın yeni hakikatini saptamak olanaklı hale gelmektedir. Her ne kadar kavram Donald Trump'ın yalan ve yanıltıcı beyanları (Baç, 2020: 19) ya da Brexit süreci ile birlikte yaygın bir şekilde gündemde yerini almış olsa da post-truth ifadesi ile ilk defa 1992 yılında Körfez Savaşı'nın 
arifesinde ödüllü senaryo ve roman yazarı Steve Tesich tarafından The Nation dergisinde yayımlanan "Amerika'nın Yoldan Çıkması" başlıklı makalede karşılaşılmaktadır (Uluk, 2018: 90). 2005 yılında ise Stephen Colbert "doğru olduğu bilinen kavram ya da olguların yerine, doğru olması istenen kavram ve olguların tercih edilmesi" anlamında "truthiness/(hakikatçilik)" (Uluk, 2018: 91) kavramına yer vermiş, lakin post-truth kelimesi çok daha yaygın bir kullanım sahasına sahip olmuştur.

2016'da Oxford Sözlüğü tarafından yılın kelimesi seçilen posttruth; "hakikat sonrası", "hakikat ötesi", "post-hakikat", "hakikatin önemsizleşmesi" ve "hakikatin değersizleşmesi" gibi kavramsallaştırmalarla kullanılmıştır. Oxford sözlük tanımına göre post-truth "ilgili ya da ona bağlı durumlarda objektif gerçeklerin kamuoyunu şekillendirmede, duygu ve kişisel inançlardan daha az etkili olması" anlamına gelmektedir (Günenç, 2019: 34; Mcintyre, 2019: 123). Uluç ve Küngerü'ye göre (2018: 1136) terim, objektif olguların, kamuoyunu şekillendirmede, duygu ve kişisel inançlara göre daha az etkili olması halini ifade etmektedir. Yani gerçeklerden ziyade duygusal argümanların etkisi söz konusudur. Bu durumun post-modernizm ile doğrudan ilişkili olduğu düşünülmektedir. Zira hakikatin izafiliği bir bakıma belirsizliği de beraberinde getirmektedir. Benzer perspektiften post-truth söylemlerinin kahir ekseriyetinin sosyal medya başta olmak üzere küresel medya ağları aracılığıyla gündeme gelmesi, küreselleşmenin bilişim-teknoloji alanında sunduğu imkanların kullanım alanlarını/sahalarını etkili kılmaktadır.

"Gerçeklik" olarak sunulan olguların mutlak şekilde doğrulanan bilgiler olmadığını, bireylere "gerçek" olarak hissettiren olgulardan oluştuğunu savunan bu kavram (Özcan, 2018: 1) mutlaklığı tartışmaya açması ile bu ilişkinin bir başka tezahürünü ifade etmektedir. Hatta henüz "truth" kavramına yönelik olarak gerçeklik ve hakikat arasındaki ilişkinin bile belirginleştirilememesi, bir bakıma flu tablo tanımını netleştirmektedir. Bu ikiliğe karşı geliştirilen bir eleştiriye göre örneğin gerçeklik tartışmaya açık olsa da hakikat öyle değildir. Çünkü hakikatin ve hakikat olmanın tek bir biçimi vardır. Bundan dolayı hakikat ve gerçeklik kavramları, koparılamayacak derecede birbirine bağlı olsalar da özdeş değillerdir (Köktürk, 2020: 36). Tartışmaya sunulan bir katkı bağlamında, gerçek, "zihinden bağımsız nesnel varlıklar"ı ifade ederken hakikat, "gerçeklerin zihindeki yansıması"nı ifade etmektedir. Dolayısıyla gerçekliğin, dış dünyada var olan nesnelerden oluştuğu, 
hakikatin ise cümleler, ifadeler, yargılar ve önermelerden oluştuğu düşünülmektedir (Uluk, 2018: 85). Bir bakıma bu girift tablonun dahi post-truth kavramına içkin doğal bir tartışma alanı olduğunu düşünmek olasıdır. Çünkü aslında kavramın deyim yerindeyse vaat ettiği bu belirsiz/müphem alandır. Dolayısıyla tartışmaları anlamlandırma çabası havanda su dövmek deyimini akıllara getirebilmektedir. Postmodernizmin tarihindeki belki de en etkili ve en meşhur hadisesi olarak kabul edilebilecek olan "Sokal Olayı"na atfen "Son Moda Saçmalar"daki şu ifade dikkat çekmektedir: "Çoğu durumda size metinler bu kadar anlaşılmaz görünüyorsa, bunun nedeni bunların tam manasıyla hiçbir anlama gelmiyor olmalarından kaynaklan(maktadır)" (Sokal ve Bricmont, 2013: 24).

Belirsizlik ve anlamsızlığın güncellenmesi boyutu ise çalışma nazarında önem arz eden bir husustur. Çünkü bu güncelleme bir meşru zemin inşasını da beraberinde getirmektedir. $\mathrm{Bu}$ ifadeyi belirginleştirmek için dün ve bugün arasında kısa bir mukayese yapmak mümkündür. Örneğin bugün Donald Trump'ın yalan ve yanıltıcı beyanları karşısındaki tutum ve tavır, bu beyanların post-truth karşısında olağan kabul edilmesi olarak bile algılanabilmektedir ve bu olağan kabul olağanüstü bir zemin oluşturmaktadır. Lakin akla daha önceki ABD başkanları gelmektedir. Nitekim örnekten hareketle daha önceki $A B D$ başkanlarının oldukça rasyonel davrandıkları, Amerikan halkına ve dünyaya yalan söylemedikleri yanılgısı oluşturularak onların söylemleri meşrulaştırımaktadır. Örneğin kitle imha silahı bulundurduğu gerekçesiyle Irak'ı işgal eden Bush dönemi Amerikan yönetimi, böyle bir post-truth söylemiyle kendi siyasetini rasyonel ve dürüst olarak gösterme fırsatı bulmakta ve meşruiyet kazanabilmektedir. Bu anlamıyla hakikat sonrası siyaset (post-truth politics) kavramının içi boş ve temelleri gevşek bir kavram olduğunu iddia etmek yanlış olmayacaktır (Güven, 2020: 23). Esas itibariyle hakikatin özüne dair tartışmalar yeni değildir, yeni olan güncellenen kavramsallaştırmalardır. Nitekim benzer bir sürecin pandemi sürecinde de var olduğu iddia edilmektedir. Çünkü nasıl ki hakikatin bu çağdaki konumu tartışılmadan hakikat-sonrasına işaret edilmişse, pandemi süreci ile ilgili olarak da henüz sürecin mevcut etkileri bile yeterince analiz edilmeden "sonraya" dair perspektifler sunulmaktadır ve şüphesiz sürecin "belirsizliği" de bu perspektife katkı sunmaktadır. 


\section{POST-COVİD: BİTMEDEN BAŞLAMAK MÜMKÜN MÜ?}

Covid-19'un küresel bir boyuta ulaşmasının ardından tıp, sosyoloji, psikoloji, iktisat, hukuk, uluslararası ilişkiler, yönetim gibi disiplinler başta olmak üzere, salgının boyutlarına ve etkilerine dair çalışmalar ve tartışmalar gündeme gelmiştir. Lakin sürecin boyutlarının ve etkilerinin analiz edilmesi nazarında çalışmanın odak noktası açısından dikkat çeken vetirelerle karşılaşılmıştır. Zira henüz salgının geleceğine dair bilimsel argümanlar tespit edilememiş olmasına karşın, yazında Covid sonrasına dair değerlendirmeler gündeme gelmiştir. Belirtmek lazımdır $\mathrm{ki}$, işbu çalışma ilgili değerlendirmelere karşı/t bir tutum geliştirmemektedir. Muhtevalarına ya da hipotezlerine dair olumlu ya da olumsuz bir yargı da ortaya koymamaktadır. Bilakis küreselleşme ve post-modernizm ekseninde bu ve benzeri değerlendirmelerin doğal kabul edilmesi gerektiğini savunmaktadır. Çünkü bu savunma bahsedilen eksenin güncellenmesine dair savı güçlendirmektedir.

Bu savın temellendirilmesi adına da birçok alanda çeşitli örneklerle karşılaşmak olasıdır. Örneğin küresel ekonomi-politik ekseninde Covid19 sonrasına veya post-Covid sürecine dair küresel sistem ve küresel ilişkilerin muhtelif yansımalarından dünya düzeninin nasıl şekilleneceğine dair (bkz. SAM, 2020; Cimmino vd., 2020; Sambur, 2020) perspektiflerle karşılaşılmaktadır. Bir başka alan açısından blockchain'in yeni dönemdeki yeri (Blockchain Türkiye, 2020) analiz edilmektedir. Covid-19 sonrası jenerasyonun gelecek öngörüsü (Buheji, 2020) gibi örnekleri de bu bağlamda zikretmek mümkündür. Hatta özgürlük ve kamu güvenliği ekseninde gelecek projeksiyonlarına dair kitle iletişim araçlarındaki öngörüleri ilave etmek yanlış olmaktadır. Elbette ki hayatın birçok noktasını etkileyen pandemi sürecine dair analiz ve yorumlara duyulan ihtiyaç kaçınılmazdır. Lakin henüz sürecin ne şekilde, hangi etkilerle ve ne zaman nihayete ereceğine dair belirgin doneler söz konusu değilken, "sonra"ya dair çalışma ve söylemler için temkinli olunması gerektiği düşünülmektedir.

Bu temkinlilik dönüşümcü yaklaşıma dair birinci bölümde zikredilen yeniden şekillenme ve değişimler dikkate alındığında "küreselleşme bitti mi?" (Yıldızoğlu, 2020) sorusuna net cevaplar verebilmek için henüz erken olduğu kanaati ile ilgilidir. Elbette ki küreselleşmenin Batı odaklı ve özellikle ABD eksenli çıkarımları göz önünde bulundurularak Batı'nın pandemi sürecindeki yaşadığı sıkıntılar ve aksaklıklar bazında böylesi bir soru sorulabilmekte ve Asya'nın ya da Çin'in yükseliş olanaklarından söz edilebilmektedir. Ancak bu 
noktada üç hususun unutulmaması gerekmektedir. Birincisi bu sürecin küreselleşme adına bir "son" olmayacağı, kriz eksenli bir geçiş süreci olabileceği de ihtimal dahilindedir. Çünkü bu kriz küreselleşmenin karşılaştığı/yüzleştiği ne ilk ne de son krizdir. İkincisi Asya'nın yükselişi yeni bir gelişme değildir. Aksine temelleri 1990'lara değin uzanabilecek bir arka plana sahiptir. Üçüncüsü ise küreselleşmenin çok-boyutluluğu gerçeğidir. Zira sınırların geçici olarak kapatılması ile insan mobilizasyonu asgari düzeye inmiş olsa da örneğin bir diğer küreselleşme boyutunda pandemi sürecinde elektronik ticaret hacminde meydana gelen artış (Güven, 2020: 256) söz konusudur. Bu nedenle pandemi sona ermeden yeni ve bilinemez bir süreci başlatmak olanaklı değildir.

Post-Covid söylemlerine yönelik bu açıklamaların haricinde pandemi ve post-truth konusuna da kısa bir ekleme yapılması gerekmektedir. Her ne kadar nicel veriler ışığında keskin ayrımlar ortaya koymak şu an için mümkün değilse de pandemi ile mücadelede yaşanan krizlerle post-truth söyleminin ön plana çıktığı ülkeler ve aktörler arasında bir ilişki kurulması olanaklı görülmektedir. Öyle ki kavramın üzerinde en çok konuşulduğu Donald Trump'ın başarısız addedilen mücadele tablosu karşısında vaka sayılarını azaltmak için test sayılarının azaltılmasını önermesi dikkat çekicidir. Ardından akıllara Brezilya Devlet Başkanı Jair Bolsonaro gelmektedir ki Bolsonaro da Covid-19'u "basit bir grip" olarak değerlendirmiş ve eleştirilerin odak noktası haline gelmiştir. Son olarak yine post-truth söylemi ile anılan Hindistan Başbakanı Narendra Modi (Sharma, 2019) gelmektedir ki yine Hindistan'da da bu mücadele ekseninde çok güçlü ve olumlu bir tablonun varlığından söz etmek güç görünmektedir. Pandemi sürecinin akıbeti hakkında çalışmanın kaleme alındığı dönemdeki bu belirsizlik dikkate alındığında post-truth'un Covid-19 perspektifindeki bu yansımalarının küreselleşmenin "post"ları arasındaki ilişkiyi ortaya koyduğu düşünülmektedir.

\section{SONUÇ}

Dünya, birçok alanda ve birçok anlamda kısa sürede yoğun içeriğe sahip gelişmelerle karşılaşmaktadır. Gelişmelerin ortaya çıkış sebepleri, etki düzeyleri ve sonuçları bazen rasyonel teşhisleri beraberinde getirirken, bazen de öngörülemeyen riskleri beraberinde getirmektedir. Soğuk Savaş sonrası dönemden bu yana terörizm, ekonomik krizler, diplomatik sorunlar, rejim değişiklikleri gibi 
hadiselerin yanı sıra küresel bir boyut kazanan salgınlar da bu ifadeyi teyit etmektedir.

Küreselleşme çok-boyutlu bağlamı içerisinde ekonomi, politika, bilişim-teknoloji ve kültür alanlarındaki yansımaları itibariyle halen teşhisler ve riskler nazarında tartışmaların odak noktası konumundadır. Bu odak noktasına dair küreselleşme özelinde çeşitli yaklaşımlarla karşılaşılmaktadır: Aşırı-küreselleşmeciler, şüpheciler/kuşkucular ve dönüşümcüler. Çalışma açısından yeniden şekillenme boyutunda dönüşümcü yaklaşımın perspektifi ön plana çıkmış ve bu perspektif post-modernizm ile olan ilişki açısından ele alınmıştır. Postmodernizmin küreselleşmeyle olan irtibatı oluşan belirsizlik bağlamında önemli ipuçları sunmuştur ve bu durum da bir güncelleme olarak değerlendirilmiştir.

Post-truth kavramı benzer bir biçimde post-modernizmin mutlağa (hakikate) yönelik eleştirisiyle bağlantılı olarak dönemin makul meşruiyet alanlarından birisini oluşturmuştur. Küreselleşme başlığı altında post-modernizm ve post-truth kavramları incelendiğinde postCovid söylemlerinin aynı bağlam içerisinde analiz edilebileceği düşünülmüştür. Zira henüz salgının etkileri ve olası sonuçları belirginleşmemişken, tıp haricindeki birçok alanda özellikle sosyal bilimler disiplinlerinde pandeminin sonrasına dair analizlerin ortaya konulması küreselleşmenin post'ları nazarında bir devamlılık olarak görülmektedir.

Bu çalışmanın kaleme alındığı zaman dilimi itibariyle 2020 yılının ikinci yarısında henüz pandeminin ne zaman ve ne şekilde sona ereceği bilinmemektedir. Bilinen şey elbette ki birçok bağlama salgının tesir edeceği yönündedir. Lakin "post" kavramsallaştırması örnekleri bile henüz küreselleşmeye dair bir "son" tartışmasını makul göstermemektedir. Bu nedenle küresel ilişkiler ve dengeler açısından da kısa sürede bir eksen değişiminden söz etmenin güç olduğu değerlendirilmektedir.

\section{KAYNAKÇA}

Artan Özoran, B. \& Mermer, A. (2018). Bauman Gibi Düşünmek: Wellness ile Ölümün Yapısökümünün Haberler Üzerinden İncelenmesi. Selçuk İletişim 11, 307-330.

Aslan, O. (2020). Post-Truth Kavramının Postmodernizm Aynası Üzerine Düşen Yansımaları. Pasajlar 2(4), 109-124. 
Baç, M. (2020). Hakikatin Savuşturulması, Ötelenmesi ve Geri Dönüşü Üzerine. Pasajlar 2(4), 17-34.

Başer, D. (2011). Zygmunt Bauman'da Müphemlik ve Toplumsal Yaşam. (Yayımlanmamış Yüksek Lisans Tezi). Afyon Kocatepe Üniversitesi, Sosyal Bilimler Enstitüsü, Sosyoloji Anabilim Dalı, Afyonkarahisar.

Bauman, Z. (2014). Parçalanmış Hayat, Postmodern Ahlak Denemeleri. (Çev.). Türkmen, İ. İstanbul: Ayrıntı Yayınları.

Bauman, Z. (2013). Postmodernizm ve Hoşnutsuzlukları. (Çev.). Türkmen, İ. İstanbul: Ayrıntı Yayınları.

Best, S. \& Kellner, D. (2011). Postmodern Teori, Eleştirel Soruşturmalar. (Çev.). Küçük, M. İstanbul: Ayrıntı Yayınları.

Blockchain Türkiye (2020). Covid-19 Sonrasında Bizi Bekleyenler ve Blockchain'in Yeni Dönemdeki Yeri.

Buheji, M. (2020). Future Foresight of Post Covid-19 Generations, International Journal of Youth Economy 4(1),1-3.

Cimmino, J. (2020). A Global Strategy for Shaping the Post-Covid19 World, Atlantic Council, Strategy Papers.

Friedman, T. (2010). Küreselleşmenin Geleceği, Lexus ve Zeytin Ağacı. (Çev.). Özsayar, E. İstanbul: Boyner Yayınları.

Guenon, R. (2020). Niceliğin Egemenliği ve Çağın Alametleri. (Çev.). Kanık, M. İstanbul: İnsan Yayınları.

Günenç, M. (2019). David Hare'in Oyunlarında Post-Truth Söylem. Konya: Çizgi Kitabevi.

Güven, A. (2020). Hakikatin Yitimi Olarak Post-Truth: Bir Kavramsallaştırma Denemesi. İnsan\&Insan 7(23), 20-36.

Güven, H. (2020). Covid-19 Pandemik Krizi Sürecinde E-Ticarette Meydana Gelen Değişimler, Avrasya Sosyal ve Ekonomi Araştırmaları Dergisi 7(5), 251-268.

Kaya, M. (2009). Küreselleşme Yaklaşımları. Dicle Üniversitesi Ziya Gökalp Eğitim Fakültesi Dergisi 13, 1-16.

Keyes, R. (2019). Hakikat Sonrası Çağ, Günümüz Dünyasında Yalancılık ve Aldatma. (Çev.). Özçetin, D. İzmir: Deli Dolu.

Koyuncu, A. A. (2019). Özgürlüğün Bir İmkânı Olarak Belirsizlik: Bauman Bağlamında Eleştirel Bir Deneme. Ekev Akademi Dergisi ICOAEF Özel Sayısı, 21-38. 
Köktürk, M. (2020). Post-Truth ya da Mağaraya Dönüş. Pasajlar 2(4), 35-55.

Mcintyre, L. (2019). Hakikat-sonrası. (Çev.). Biçici, M. F. İstanbul: Tellekt.

McLuhan, M. (1964). Understanding Media: The Extensions of Man. New York/London: McGraw-Hillpaperback.

Nikiforuk, A. (2013). Mahşerin Dördüncü Atlısı, Salgın ve Bulaşıcı Hastalıklar Tarihi. (Çev.). Erkanlı, S. İstanbul: İletişim Yayınları.

Özcan, M. (2018). Öznenin Ölümü: Post-Truth Çağında Güvenlik ve Türkiye. Insamer, 1-12.

Rorty, R. \& Vattimo, G. (2009). Dinin Geleceği. (Çev.). Öğdül, R. G. İstanbul: Ayrıntı Yayınları.

Russ, J. (2014). Avrupa Düşüncesinin Serüveni, Antik Çağlardan Günümüze Batı Düşüncesi. (Çev.). Doğan, Ö. Ankara: Doğu Batı Yayınları.

Sambur, B. (2020). Covid 19 Sonrası Dünya Düzeni. İstanbul: Orion. Sharma, G. K. (2019). The Post-Truth Era: An Analysis with Reference to Contemporary Politics. DLR 11(1), 1-6.

Sokal, A. \& Bricmont, J. (2013). Son Moda Saçmalar, Postmodern Aydınların Bilimi İstismar Etmesi. (Çev.). Gönülşen, B. İstanbul: Alfa Bilim.

Tomlinson, J. (2013). Küreselleşme ve Kültür. (Çev.). Eker, A. İstanbul: Ayrıntı Yayınları.

Türkiye Cumhuriyeti Dışişleri Bakanlığı Stratejik Araştırmalar Merkezi (SAM). (2020). Covid-19 Sonrası Küresel Sistem, Eski Sorunlar, Yeni Trendler. Ankara.

Uluç, G. \& Küngerü, A. (2018). Yeni Gerçek-Ötesi Dönem (PostTruth): Birleşik Krallık Tabloid Gazetelerde Brexit Referandumu İncelemesi. Route Educational and Social Science Journal 5(1), 1134-1152.

Uluk, M. (2018). Hakikat Sonrası Çağda Yeni Medya \& Yalan Haber. Eskişehir: Dorlion Yayınları.

Yıldızoğlu, E. (2020). Koronavirüs (Covid-19) Sonrası Küreselleşme Bitti Mi, Yeni Süreci Çin mi Yönetecek?. Erişim Adresi: https://www.bbc.com/turkce/haberler-dunya-51955474, Erişim Tarihi: 03.03.2020. 